\title{
SOBRE EDUCAR (E SER EDUCADA POR) MULHERES TRABALHADORAS TERCEIRIZADAS NOS SERVIÇOS DE LIMPEZA DA UNIVERSIDADE FEDERAL DA BAHIA: UMA EXPERIÊNCIA DE EXTENSÃO
}

Renata Queiroz Dutra ${ }^{1}$

\section{Resumo:}

Este resumo se volta ao compartilhamento de experiência de extensão desenvolvida no âmbito da Universidade Federal da Bahia com trabalhadoras terceirizadas os serviços de limpeza. Foi desenvolvido, a partir de uma iniciativa estudantil, um curso de extensão para formação de mulheres em direitos humanos e feminismo (originalmente denominado "Promotoras legais populares"), voltado à educação dessas trabalhadoras. Durante o curso, demissões em massa surpreenderam os envolvidos, dando azo a mobilizações de estudantes, trabalhadores e professores, que permitiram debater criticamente as relações de gênero e o trabalho terceirizado, numa experiência de formação e organização que teve o estudo do direito como mediador.

\section{Palavras-chave:}

Educação jurídica, gênero, trabalho, terceirização, organização sindical

\section{ABOUT EDUCATING (AND BEING EDUCATED BY) FEMALE OUTSOURCED WORKERS IN THE CLEANING SERVICES OF THE FEDERAL UNIVERSITY OF BAHIA: AN ORGANIZATION EXPERIENCE}

\begin{abstract}
:
This paper aims to share an extension experience developed at the Federal University of Bahia with female outsourced workers of cleaning services. From a student initiative, an extension course proposed to educate women in human rights and feminism (originally called "Popular Legal Promoters") was developed. During the course, mass layoffs surprised those involved, giving rise to mobilizations of students, workers and teachers, which allowed a critical debate on gender relations and outsourced work, in a training and organization experience that had the study of law as mediator
\end{abstract}

\section{Keywords:}

Legal education, gender, work, outsourcing, union organization

\section{Introdução}

Este artigo se volta ao compartilhamento e reflexão sobre experiência de extensão desenvolvida no âmbito da Faculdade de Direito da Universidade Federal da Bahia com trabalhadoras terceirizadas os serviços de limpeza.

Em dezembro de 2017, o Coletivo Madás - grupo de estudantes feministas da Faculdade de Direito da UFBA, formulou o projeto de um curso de extensão para formação de mulheres em direitos humanos e feminismo, inspirado na experiência do projeto "Promotoras

\footnotetext{
${ }^{1}$ Professora Adjunta da Faculdade de Direito da UFBa. Doutora e Mestra em Direito, Estado e Constituição pela Universidade de Brasília.
} 
legais populares", criado em Porto Alegre, no Rio Grande do Sul, pela Organização Não Governamental Themis e replicado em outras Universidades do país, a exemplo da Universidade de Brasília.

De acordo com a ONG Themis, o projeto foi criado em 1993, tendo por objetivo "repensar o campo jurídico visando a garantir o acesso à justiça a todas as mulheres", e constituiu-se em um efetivo instrumento de afirmação e disseminação dos direitos humanos das mulheres, particularmente em relação à violência doméstica e aos direitos sexuais e direitos reprodutivos. Vinte anos após a criação, o projeto encontra-se implementado em 14 municípios do Estado do Rio Grande do Sul e em 11 estados brasileiros (INSTITUTO THEMIS, sítio virtual).

A formulação original do Projeto tinha por objetivo qualificar lideranças comunitárias femininas em noções básicas de Direito, direitos humanos das mulheres, organização do Estado e do Poder Judiciário, dentre outras temáticas pertinentes conforme o contexto do bairro ou região na qual estão inseridas. O curso, em sua projeção original, compreendia uma formação de 80 horas/aula, a partir das quais "as PLPs atuam voluntariamente em suas comunidades na defesa, orientação e triagem de demandas de violação de direitos; na prevenção de violações, através da educação socio comunitária, e na promoção de direitos, com participação e representação em conselhos, conferências, comissões e fóruns" (INSTITUTO THEMIS, sítio virtual).

As diversas experiências do curso de formação de promotoras legais populares encontram-se hoje articuladas em rede, de modo que são promovidos encontros entre as excursistas de diversas localidades, visando o fomento da atuação de cada uma delas (FONSECA, 2012).

A experiência mais próxima com a qual o Coletivo Madás dialogou para a construção da proposta foi o Programa PLP da Universidade de Brasília, na qual se inspirou mais diretamente. Entretanto, tendo em vista as dificuldades de um projeto piloto, algumas adaptações foram feitas, no intuito de viabilizar a primeira edição do curso em Salvador.

Não contando, de início, com um público específico interessado no curso, nem mesmo com um local para o desenvolvimento das atividades em regiões periféricas da cidade de Salvador, e considerando a latente demanda dos trabalhadores terceirizados da Universidade por conhecimento, organização e respeito aos seus direitos, bem como atividades de integração com a comunidade acadêmica, as quais já vinham sendo tratadas por outros grupos estudantis - como o SAJU - Serviço de apoio jurídico -, as duas ideias foram reunidas em uma proposta. 
Essa proposta consistiu em oferecer um curso de formação anual para as trabalhadoras terceirizadas da Universidade, a acontecer no horário e local de trabalho. Para as estudantes, era essencial que o projeto observasse um recorte de gênero, ainda que a expressiva maioria dos trabalhadores de limpeza fossem mulheres.

Assim, foi construída uma atividade de formação voltada à educação das mulheres trabalhadoras dos serviços de limpeza da Universidade, que são contratadas de forma terceirizada, cuja viabilidade teve como requisito essencial que o curso acontecesse nos dias e horários de trabalho, com prévia liberação da Direção das Unidades de ensino, em acordo com a empresa prestadora dos serviços de limpeza (Empresa Liderança), para que as trabalhadoras frequentassem o curso.

Isso porque, em se tratando de trabalhadoras que cumprem jornada de segunda-feira a sábado, demandar horários de realização do curso no sábado a tarde ou mesmo após a jornada de trabalho, durante os dias da semana, implicaria delas exigir um compromisso insustentável a princípio: tomar o tempo "livre" das atividades produtivas que é empregado no trabalho doméstico desenvolvido em favor de suas famílias, ou, ainda, comprometer o tempo dedicado a outras atividades econômicas por elas desempenhadas como complemento de renda (algumas fazem comidas e lanches para vender, outras vendem cosméticos na informalidade, entre outras atividades). Sendo essa a primeira experiência de formação para a maioria das mulheres, se percebeu que providenciar um horário que não concorresse com outras atividades poderia servir como condição de viabilidade da presença.

Entretanto, como a negociação das "liberações" envolvia faltar ao serviço, não foi possível garantir mais do que um encontro presencial ao mês. Desse modo, o curso foi organizado para acontecer entre abril e dezembro, abrangendo um encontro mensal presencial, sempre no sábado pela manhã, e "encontros"/atividades virtuais, que garantiriam a frequência quinzenal da atividade.

Dessa forma, deu-se início a um projeto de extensão, devidamente formalizado perante as instâncias administrativas da Universidade, que replica experiência extensionista consolidada na Faculdade de Direito da Universidade de Brasília (Projeto Promotoras Legais Populares/ O Direito Achado na rua) propondo a realização de um curso permanente de educação jurídica popular voltado para a formação de mulheres de qualquer escolaridade, e tendo por objetivo a sua capacitação em noções de Direito, gênero e cidadania. A proposta era de que, ao final do programa, que teria duração de oito meses para cada turma, as integrantes 
recebessem o título simbólico de Promotoras Legais Populares, ficando capacitadas para atuarem na defesa dos seus direitos e de outras mulheres de suas comunidades.

Desse modo, a proposta cumpriria os objetivos de proporcionar às estudantes extensionistas uma formação crítica e humanística, a partir do contato com demandas sociais (as atividades consistem na preparação e realização de debates, oficinas e atividades de militância mediados por profissionais de diferentes áreas, e, eventualmente, pelas próprias extensionistas e equipe) e às trabalhadoras um momento de formação, integração à comunidade acadêmica, bem como de conscientização e empoderamento para defesa dos direitos humanos.

O desenrolar da atividade demonstrou que o curso tem constituído um importante espaço de visibilidade, organização coletiva e diálogo a partir da experiência do trabalho feminino precário e terceirizado, assim como tem possibilitado a reflexão a respeito da distância, dos estranhamentos e dos limites relativos à noção de direitos, cidadania e justiça.

É a partir dessa experiência que se deitam as reflexões desse ensaio.

\section{A reformulação do plano do curso pelas trabalhadoras: a centralidade do trabalho!}

A proposta foi desenvolvida tendo como lastro a metodologia da Educação Popular, com respaldo nos estudos de Paulo Freire, na releitura empreendida por Bell Hooks (2013), que orientam a educação como prática de liberdade, que questiona, no próprio ato de educar, a reprodução de estruturas sociais de dominação e hierarquia.

Como ensina Hooks, para lecionar em comunidades diversas, precisamos mudar não só nossos paradigmas, mas também o modo como pensamos, escrevemos e falamos: "a voz engajada não pode ser fixa e absoluta. Deve estar sempre mudando, sempre em diálogo como o mundo fora dela" (2013, p. 22).

Tentando tomar tal perspectiva como horizonte, tão logo a turma se formou, foi oportunizado às cursistas a realização de um pacto de convivência para o decorrer do curso e foram apresentados os termos da proposta, com abertura para suas sugestões e reformulações.

$\mathrm{Na}$ proposta original, o curso seria realizado nas seguintes datas e com as seguintes perspectivas temáticas, encadeadas em ordem preferencial:

- $\quad$ 14/abril (8h00 às 12h00) Apresentação do Curso e das participantes ;Celebração do Pacto de convivência ; Noções introdutórias de gênero: Por que um curso de formação para mulheres? 
- $\quad 12 /$ maio ( $8 \mathrm{~h} 00$ às $12 \mathrm{~h} 00) \quad$ Representações de gênero, papeis sociais e resistências: o que é ser mulher? Apreendendo possibilidades e potencialidades a partir das ideias de igualdade, inclusão e cidadania.

- $\quad 16 / j u n h o ~(8 h 00$ às $12 \mathrm{~h} 00) \quad$ Mulheres, papeis na família e trabalho doméstico: Como o direito de família e o direito do trabalho podem proteger as mulheres no âmbito do lar? - $\quad 7 / j u l h o ~(8 h 00$ às $12 \mathrm{~h} 00) \quad$ Violência contra a mulher e Lei Maria da Penha

- $\quad 4 / a g o s t o ~(8 h 00$ às $12 \mathrm{~h} 00) \quad$ Encarceramento feminino e noções de criminologia: um debate sobre a comunidade e o papel da mulher nela.

- $15 /$ setembro (8h00 às $12 \mathrm{~h} 00) \quad$ Direito do Trabalho e terceirização

- $\quad 20 /$ outubro (8h00 às $12 \mathrm{~h} 00)$ Previdência Social

- $10 /$ novembro ( $8 \mathrm{~h} 00$ às $12 \mathrm{~h} 00) \quad$ Políticas públicas e mulheres: a saúde das mulheres e o SUS

- $\quad 1 /$ dezembro (8h00 às 12h00) Direitos humanos e organização coletiva

- $\quad 15 /$ dezembro $(8 \mathrm{~h} 00$ às $12 \mathrm{~h} 00) \quad$ Formatura da Turma

Embora a proposta inicial do curso se envolvesse debates a respeito de gênero, papéis das mulheres na família, direito de família, violência contra a mulher, criminologia feminista, entre outros, o início da atividade foi marcado pela discussão horizontal do conteúdo e do cronograma com as participantes, que imediatamente solicitaram que as temáticas do direito do trabalho e da seguridade social fossem discutidos com prioridade sobre os demais assuntos propostos.

A questão dos direitos trabalhistas, bem como, em segundo plano, das possibilidades de aposentadoria e pensionamento se mostraram como conhecimentos e demandas centrais para a experiência daquelas mulheres, que desejavam não apenas conhecer e aprender sobre direitos (que haviam sido modificados pela recente Reforma na legislação trabalhista e estavam ameaçados pela iminência de uma Reforma Previdenciária), mas, sobretudo, utilizar aquele espaço, em que seriam ouvidas por estudantes e professoras, para denunciar as violações de seus direitos e cobrar respostas da Universidade, dos sindicatos e da comunidade acadêmica.

A situação do trabalho terceirizado no âmbito da Universidade é dramática: embora se observe um progressivo crescimento do número de trabalhadores contratados para atividades das mais diversas ordens (limpeza, portaria, segurança, auxílio administrativo, entre outras), 


\section{SOBRE EDUCAR (E SER EDUCADA POR) MULHERES TRABALHADORAS TERCEIRIZADAS NOS SERVIÇOS DE LIMPEZA DA UNIVERSIDADE FEDERAL DA BAHIA: UMA EXPERIÊNCIA DE EXTENSÃO}

em detrimento do crescimento do número de servidores ${ }^{2}$, as violações de direitos trabalhistas e a precarização do trabalhado desses sujeitos é preocupante, como observam Druck, Sena, Pinto e Araújo, em pesquisa realizada na UFBA no ano de 2015 (2018).

Essa situação inicial já se apresentou como aprendizagem para as estudantes envolvidas no projeto: embora a formação originária do grupo não se restringisse ao feminismo liberal, havia um destacado interesse das estudantes na discussão de gênero a partir do viés da violência (física, psicológica e patrimonial contra a mulher), notadamente em face de estudos sobre criminologia e questões relacionadas à família. Aliás, a própria inserção das temáticas relacionadas ao trabalho no curso relacionava-se a uma exigência das professoras coordenadoras, sem muito eco entre as extensionistas.

O fato de a demanda pelos conhecimentos sobre o direito do trabalho e demais direitos sociais vir por iniciativa das trabalhadoras, bem como o próprio pedido de prioridade em relação aos demais, representou uma especial compreensão do universo vivenciado por aquelas mulheres, em relação às quais a vivência das questões de gênero, raça e classe se apresentava de modo consubstancial. Dessa forma, a vivência da condição feminina, com toda a sua singularidade, não poderia ser debatida de modo apartado das demais condições e recortes que atravessavam a vida dessas mulheres. A condição de mulher, negras e trabalhadoras precárias se sobrepunham nas discussões, embora as próprias trabalhadoras tenham reivindicado por primeiro a questão material que lhes pareceu mais urgente.

O conceito de consubstancialidade, entendido como "unidade de substância", evidencia que a diferenciação dos tipos de relações sociais é uma operação por vezes necessária à sociologia, mas que é analítica, e não pode ser, por isso, aplicada inadvertidamente e à análise das práticas sociais concretas. Isso porque as relações sociais formam um nó que não pode ser desatado no nível das práticas sociais, mas apenas na perspectiva analítica. E as relações sociais são também coextensivas: ao se desenvolverem, as relações sociais de classe, gênero e raça se reproduzem e se co-produzem mutuamente. Deve-se atentar para o fato de que a ideia de consubstancialidade não implica que tudo está relacionado a tudo, mas constitui apenas uma forma de leitura da realidade social (KERGOAT, 2010).

Outra questão que foi colocada nesse momento inicial referiu-se à participação dos trabalhadores do sexo masculino: como na Faculdade de Direito, onde o curso foi realizado, só

\footnotetext{
${ }^{2}$ Em 2006, os terceirizados representavam 15\% do total dos trabalhadores da UFBA, enquanto os servidores técnico-administrativos eram $49 \%$. Em 2015 , chegaram a $27,5 \%$, próximo ao que representava o número de docentes $(29,7 \%)$, enquanto a participação dos servidores caiu para 41\% (DRUCK, SENA, PINTO, ARAÚJO, 2018).
} 
haviam 3 homens nos serviços de limpeza e eles também se mostraram interessados em participar do curso, houve um certo constrangimento inicial em recusar sua presença. A questão foi colocada para as trabalhadoras no primeiro encontro e elas decidiram que, em relação a alguns temas (como, por exemplo, trabalho e previdência), os homens poderiam ser convidados a participar. No entanto, afirmaram reconhecer como importante que o espaço fosse criado e prioritário para elas nos demais momentos.

Igualmente interessante foi o fato de que, no mês de setembro, as trabalhadoras, após a criação de um laço de confiança e da abertura do canal de diálogo com o grupo, voltaram a intervir na programação, solicitando uma atividade específica sobre assédio sexual no trabalho, uma vez que estavam vivenciando essa situação em relação a um outro trabalhador terceirizado.

Novamente, o espaço do curso se apresentou como momento de resistência, uma vez que a proposta da realização de uma atividade, incluindo os homens, tinha por objetivo intimidar a conduta do colega, que, por diversas razões, a elas não interessava denunciar.

Assim, a discussão sobre violência sexual aconteceu, de modo prioritário e a pedido das cursistas, num contexto diverso daquele para os quais as estudantes haviam se preparado: a perspectiva da violência sexual no trabalho.

Desse modo, as atividades do curso acabaram se realizando efetivamente da seguinte forma:

- $\quad$ 14/abril (8h00 às 12h00) Apresentação do Curso e das participantes; Celebração do Pacto de convivência ; Noções introdutórias de gênero: Por que um curso de formação para mulheres?

- $\quad 12 /$ maio (8h00 às $12 \mathrm{~h} 00) \quad$ Representações de gênero, papeis sociais e resistências: o que é ser mulher? Apreendendo possibilidades e potencialidades a partir das ideias de igualdade, inclusão e cidadania.

- $16 / j u n h o(8 h 00$ às $12 \mathrm{~h} 00) \quad$ Direito do Trabalho e terceirização

- $\quad 7 / j u l h o(8 h 00$ às $12 \mathrm{~h} 00) \quad$ Previdência Social

- $\quad 4 / a g o s t o ~(8 h 00$ às $12 \mathrm{~h} 00) \quad$ Encontro com as entidades sindicais

- $15 /$ setembro (8h00 às 12h00) Direitos humanos e organização coletiva

- $\quad * 19 / 10 / 2018$ (12h00 às 13h30) Encontro extra sobre assédio moral e sexual no trabalho

- 20/outubro (8h00 às 12h00) Mulheres, papeis na família e trabalho doméstico: Como o direito de família e o direito do trabalho podem proteger as mulheres no âmbito do lar? 
SOBRE EDUCAR (E SER EDUCADA POR) MULHERES TRABALHADORAS

TERCEIRIZADAS NOS SERVIÇOS DE LIMPEZA DA UNIVERSIDADE FEDERAL DA BAHIA: UMA EXPERIÊNCIA DE EXTENSÃO

- $10 /$ novembro $(8 \mathrm{~h} 00$ às $12 \mathrm{~h} 00) \quad$ Violência contra a mulher e Lei Maria da Penha

- $\quad 1 /$ dezembro (8h00 às 12h00) Políticas públicas e mulheres: a saúde das mulheres e o SUS

- $15 /$ dezembro (8h00 às $12 \mathrm{~h} 00) \quad$ Formatura da Turma

\section{As dispensas imotivadas em massa}

Concomitantemente ao desenvolvimento do curso (previsto para durar um ano), foi iniciada no âmbito da Universidade uma onda de dispensas imotivadas, promovida pela empresa prestadora de serviços de limpeza, que atingiu um número estimado de 90 trabalhadores.

Essa questão, que mobilizava tanto a solidariedade com relação aos trabalhadores e trabalhadoras já dispensadas, como o medo que se instalou entre os demais de serem dispensados, tensionou as participantes do curso e acabou inclinando as discussões para essa temática premente.

Isso aconteceu pouco depois de as trabalhadoras, como visto, por iniciativa própria terem eleito os temas "Direito do Trabalho" e "Direito Previdenciário" para iniciarem as atividades.

Por uma infeliz coincidência, duas semanas antes da realização do encontro de junho, destinado para discussão do direito do trabalho, uma das trabalhadoras que havia iniciado o curso de formação, lotada na Faculdade de direito, veio a ser dispensada, juntamente com outros cinco trabalhadores, dispersos na Faculdade de Educação e no Instituto de Saúde coletiva. Todos esses trabalhadores prestavam serviços à Universidade há mais de 7 anos (alguns deles somavam 20 anos a UFBA!), sendo, portanto, anteriores à empresa de prestação de serviços que ora os demitia.

A aproximação da trabalhadora dispensada em relação aos estudantes e a experiência de agregação colocada pelo curso permitiu uma significativa mobilização contra a sua dispensa, rendendo a produção de um abaixo-assinado, com mais de 200 assinaturas e, ainda, a articulação com um grupo de professoras da Faculdade de Educação, que estava empenhado em reverter as dispensas dos dois trabalhadores vinculados àquela unidade.

Os abaixo-assinados foram encaminhados à Pró-Reitoria de Administração da UFBA e desse primeiro contato foi agendada uma reunião com o próprio Reitor, no sentido de pressionar a Universidade à adoção de medidas contra as dispensas arbitrárias, na qual 
estiveram presentes os Diretores das duas Unidades envolvidas. A Pró-reitora de Administração, ciente dos fatos, notificou a empresa terceirizada, que, em resposta, apontou as dispensas como sendo relacionadas à assiduidade dos empregados e destacou que a Universidade não deveria intervir nas relações entre a empresa terceirizada e seus empregados, lhe cabendo somente fiscalizar a execução do serviço.

O que chamava atenção, no caso, era que a inassiduidade apontada pela empresa terceirizada em relação aos empregados dispensados, se relacionava com faltas justificadas, amparadas por atestados médicos. Ou seja, precisando enxugar quadros (e depois se soube que a empresa estava a aproveitar empregados "apadrinhados" de outro contrato de prestação de serviços com ente público que havia perdido por não renovação, resolvendo a situação desses trabalhadores por meio da substituição de empregados que prestavam serviços à UFBA, contrato ativo), a empresa elegeu aqueles que haviam faltado, ainda que justificadamente, para penalizar. Isso implicava criar um clima de temor em relação aos empregados que permaneciam, que se viam constrangidos a trabalhar ainda que adoentados.

As dificuldades concretas proporcionadas pela contratação terceirizada do serviço de limpeza se apresentaram às estudantes de uma forma mais clara que qualquer atividade de ensino em sala de aula permitiria observar.

$\mathrm{Na}$ ocasião, as estudantes engajadas no curso colaboraram na construção de uma segunda notificação da Pró-Reitoria de Administração para a empresa terceirizada, contendo, em síntese, os seguintes argumentos:

1) A contratada não junta à sua resposta qualquer comprovação das substituições eventuais dos trabalhadores ora dispensados, concernentes aos dias em que supostamente foram inassíduos, o que evidencia o descumprimento do disposto no item 13.11 do contrato, circunstância que igualmente aconteceu, segundo os dirigentes das respetivas Unidades, nos dias do aviso prévio em que os quatro trabalhadores foram liberados do serviço;

2) A contratada não infirma o registro contido na notificação, no sentido de que as faltas imputadas aos trabalhadores ora dispensados se tratavam de faltas justificadas por motivo de saúde, o que leva à presunção de veracidade desse fato.

3) Assim sendo, o que a contratada denomina inassiduidade, como motivo declarado em resposta como suficiente para a substituição dos trabalhadores (leia-se, dispensa imotivada), em verdade, consiste em ocorrência hodierna da contratação do trabalho humano, impassível de consequências jurídicas trabalhistas de acordo com a nossa ordem Constitucional (art. $1^{\circ}$, III e IV, da CF/88). 
4) Vale salientar, que para além da irregularidade contratual consubstanciada na dispensa e substituição de trabalhadores treinados, bem adaptados e cuja produtividade/resultados já foram atestadas pelos fiscais do contrato, em prejuízo da prestação de serviços, é certo que, de acordo com a ordem jurídica vigente, é reconhecido o direito potestativo do empregador de realizar dispensas imotivadas (ou sem justa causa), desde que assuma os encargos rescisórios dela decorrentes. Todavia, a ordem jurídica não alberga, em nenhuma circunstância, o abuso do direito. E, no caso, a conduta abusiva reside precisamente em dispensar, como forma de retaliação, trabalhadores que faltaram ao serviço apresentando atestados médicos. Na condição de empregadora, portanto, a CONTRATADA descumpre a legislação trabalhista na medida em que faz uso do seu poder diretivo para retaliar os trabalhadores enfermos ou que apresentaram sinais de enfermidade e, por consequência, instiga/ameaça os demais trabalhadores a comparecerem ao serviço mesmo nas hipóteses em que sejam acometidos de doença. A prática, que é ilícita, engendra o fenômeno do presenteísmo, assim denominado pela medicina do trabalho o comparecimento de trabalhadores ao serviço a despeito de suas limitações físicas, o que pode agravar quadros clínicos que seriam de simples recuperação quando guardado o repouso e/ou ocasionar contágio dos demais trabalhadores, servidores e estudantes que frequentam o meio ambiente laboral, além de propiciar, a médio e longo prazo, o ocultamento e, portanto, a ausência de notificação de doenças ocupacionais.

5) É cediço que a reponsabilidade da Administração Pública pelas obrigações trabalhistas decorrentes dos contratos de prestação de serviços só é elidida se o ente público comprova que procedeu à escorreita fiscalização da observância do cumprimento das obrigações da CONTRATADA (ADC 16-DF, STF). Ademais, o Tribunal Superior do Trabalho reiteradamente tem firmado a responsabilidade SOLIDÁRIA da Administração Pública pelas obrigações justrabalhistas devidas nos casos de acidentes de trabalho (entre os quais estão incluídas as doenças ocupacionais), por força do art. 942 do Código Civil (v.g. AIRR - 27500-30.2005.5.15.0032 Data de Julgamento: 08/05/2018, Relator Ministro: José Roberto Freire Pimenta, $2^{a}$ Turma, Data de Publicação: DEJT 11/05/2018). Em relação às obrigações concernentes à saúdo no meio ambiente laboral, aliás, a própria Organização Internacional do Trabalho, por meio do art. 17 da Convenção $\mathrm{n}^{\circ} 155$, reconhece serem indistintamente responsáveis o tomador de serviços e o empregador, previsão internacional que é corroborada pelos arts. $225, \S \S 2^{\circ}$ e $3^{\circ}$, e 200 , VIII, da Constituição Federal.

6) Portanto, para além da situação particular dos quatro trabalhadores dispensados imotivadamente, tendo tomado ciência das supramencionadas ocorrências, a CONTRATANTE possui legítimo interesse jurídico em fiscalizar (item 20.1 do Termo de Referência que integra o contrato) e coibir práticas ilícitas da contratada que revelem 
um padrão de gestão do trabalho incompatível com o zelo pelas condições de saúde e segurança dos trabalhadores envolvidos (como manda, aliás, o item 13.42.15 do Termo de Referência que integra o contrato), notificando e sancionando práticas ilícitas que possam ocasionar, além de prejuízo à integridade física e mental dos trabalhadores terceirizados, ônus financeiros futuros ao erário.

7) Nesse passo, fique a CONTRATADA notificada e advertida a respeito da necessidade de revisão do seu padrão gerencial ilícito e das dispensas igualmente eivadas de ilicitude, sob pena de incidência de sanção administrativa, bem como sob pena de que sejam oficiadas as instâncias competentes (Superintendência Regional do Trabalho e Ministério Público do Trabalho) para adoção das medidas que considerarem pertinentes.

8) Saliente-se que a intolerância com práticas gerenciais ilícitas não se confunde com ingerência ou com "reações emotivas", senão com o fiel cumprimento dos princípios constitucionais aos quais está adstrita a Administração Pública, e, especialmente, um centro de produção de conhecimento, inclusão e cidadania, como é a Universidade Pública.

Apesar dos esforços, as dispensas efetivadas não foram revertidas. As trabalhadoras que permaneceram no curso, entretanto, não foram dispensadas, o que pode revelar, ao menos, que as mobilizações serviram para intimidar novos atos por parte da empresa terceirizada.

Nesse sentido, aquela que era uma atividade de formação se desdobrou numa interessante atividade de organização coletiva, que "implodiu" o conteúdo programático inicialmente pensado para o curso e implicou a conversão dos momentos dos encontros em sala de aula em momentos de discussão, organização e articulação a respeito das condições de trabalho terceirizado na Universidade.

$\mathrm{O}$ encontro de junho acabou contando com a presença de todos os professores articulados em torno da reversão das demissões e aconteceu de forma aberta, abrangendo trabalhadores de diversas unidades. Ainda como saldo desse momento de mobilização, ocorreu na Faculdade de Educação, no final do mês, o denominado "Arraiá da resistência”, em formato de festa junina, em que professores e trabalhadores se reuniram para celebrar e para se fortalecer. As cursistas integraram essa atividade.

\section{A questão sindical e a organização coletiva}

Outra questão que se projetou a partir do episódio das dispensas coletivas foi: onde estavam os sindicatos? Toda a mobilização em torno dos dispensados aconteceu sem que 
nenhum sindicalista acompanhasse o fato. A partir daí, tomamos a iniciativa de identificar o sindicato responsável e contatá-los. Para surpresa geral, o sindicato que as trabalhadoras criam ser o seu legítimo representante (SINDILIMP) havia sido, há mais de um ano, destituído da legitimidade para representar a categoria, por força de decisão judicial, e até o momento, o novo representante - Sintral - ainda não havia se apresentado às trabalhadoras.

Considerando que no Brasil vige a regra da unicidade sindical imposta pela Constituição e que, até a reforma trabalhista que passou a vigorar em novembro de 2017, era obrigatória a contribuição sindical, a categoria dos trabalhadores e trabalhadoras da limpeza, no âmbito da cidade de Salvador, estava sendo disputada judicialmente por dois sindicatos.

Essa informação foi passada às trabalhadoras do curso pelas estudantes e professoras envolvidas na atividade, uma vez que nenhum dos dois sindicatos era conhecido ou estava em diálogo com as trabalhadoras, de modo que foi necessário, a pedido das trabalhadoras, e como demanda decorrente do curso, que dois encontros fossem destinados a convidar os sindicatos e confrontá-los a respeito das demandas concretas, da necessidade de diálogo, representação e luta.

Os encontros com ambas as entidades sindicais foram frustrantes. $\mathrm{O}$ distanciamento $\mathrm{e}$ o desinteresse nas questões da categoria eram profundos e revelavam muito mais uma disputa de poder pela base e pela fonte de financiamento que ela representa do que um compromisso com os trabalhadores e suas questões. Houve troca de acusações entre os dirigentes de cada uma das entidades sindicais e a apresentação de uma relação burocratizada com os trabalhadores, que eram culpabilizados por desconhecerem as informações e o funcionamento do sindicato, assim como pelo próprio desconhecimento dos sindicatos a respeito das questões que eles vivenciavam, já que eles não teriam sido diligentes em “denunciar” ao sindicato.

Foi a partir dessas experiências negativas que a foi puxada a atividade da organização coletiva, por meio da qual se suscitou entre as trabalhadoras a necessidade de organização e ação protagonizada por elas mesmas, sem esperar pela condução sindical. Nesse sentido, foi compartilhada a bela experiência da greve das trabalhadoras terceirizadas da USP, que é narrada na obra “A precarização tem rosto de mulher” (ASSUNÇÃO, 2013).

No que concerne à condição de terceirizados, é interessante observar que, a materialidade da divisão entre terceirizados e contratados diretamente produz impactos significativos na organização sindical. Sendo os servidores da Universidade (docentes e técnicos administrativos) enquadrados em entidades sindicais próprias (APUB e ASSUFBA), que dialogam entre si e transitam nas instâncias da Universidade, fica muito evidente o processo 
de exclusão e alheamento do sindicato dos trabalhadores terceirizados em relação ao contexto onde as trabalhadoras se inserem.

Graça Druck explica sobre a dificuldade de consolidação de um sentido de alteridade no trabalho terceirizado, que contribui para a formação de novas identidades sociais individualizadas em detrimento daquelas coletivas,

Esse processo tem sérias implicações sobre a relação dos trabalhadores entre si e com o trabalho, determinando novas identidades sociais. Em geral, extremamente frágeis, à medida que a referência deixa de ser coletiva ou sustentada em coletivos de trabalhadores e passa a ser individual, fragmentada e incentivada pela solidão do mercado.[...] Essa individualização leva à quebra do sentimento de pertencimento social, reforçado pela ausência de construção de identidades de interesses, forjadas na experiência coletiva, e que é fundamental para a construção de uma identidade de classe (DRUCK, 1999).

Também cabe aqui a relevante observação de Paula Marcelino no sentido de que a heterogeneidade da categoria, por si só, não é determinante na debilidade de uma atuação sindical. A autora reivindica à classe trabalhadora, historicamente, condições heterogêneas que em certos momentos históricos potencializaram lutas, de modo que, ao analisar experiências diversas de luta sindical entre terceirizados, pontua que não é o caráter heterogêneo dos grupos estudados que determina ações sindicais fortes ou frágeis, mas sim as escolhas políticas que são feitas na construção das lutas (MARCELINO, 2013).

Outra questão que aprofunda a falta de representatividade sindical é a questão de gênero. Em que pese a composição de gênero da categoria seja feminina, esse quadro não reverbera, por exemplo, na presença paritária de mulheres nos diversos espaços de decisão e fala do sindicato, nem mesmo no comprometimento das negociações coletivas com pautas femininas.

A invisibilização da questão de gênero da categoria no espaço do sindicato, aliada a diversos outros componentes do machismo em escala estrutural (como a dupla jornada de trabalho e a subestimação política das mulheres (GODINHO, 1996)), fazem com que as desigualdades de gênero presentes na sociedade se reproduzam no espaço sindical e comprometam a efetiva representação dos inconformismos e das resistências femininas, na forma como elas os percebem e expressam.

Como pontua Elizabeth Souza Lobo, existem formas de organização e de reivindicação (bem como suas temáticas) que decorrem de "um modo feminino e um masculino de pertencer 
à classe operária" e que devem ser consideradas em suas peculiaridades para a efetiva integração das trabalhadoras a esse espaço de representação:

a divisão sexual do trabalho se constrói como estratégia de gestão da força de trabalho, através de representação e de linguagem do capital, tanto quanto como estratégia de resistência das mulheres e dos homens nas relações com o trabalho e suas práticas sociais (SOUZA LOBO, 2011).

Marilane Teixeira e Eugênia Leone observavam, inclusive em nível nacional, a reprodução das desigualdades de gênero, notadamente quando implicam em nichos de trabalho precário femininos, não só entre empregadores e empregadas, mas também no seio das entidades sindicais, salientando a disposição de homens e mulheres nas hierarquias sindicais:

Os espaços sindicais, em alguma medida, irão reproduzir o mesmo processo de exclusão e marginalização que as mulheres enfrentam nos ambiente de trabalho. Embora lutem pelo reconhecimento no mercado de trabalho, as mulheres seguem sendo minoria nos sindicatos e não estão presentes nas posições de destaque como residência, secretaria geral e tesouraria. Como se pode deduzir a divisão sexual do trabalho contida na noção de gênero continua a perpassar fortemente a s relações entre homens e mulheres no interior dos sindicatos (TEIXEIRA, LEONE, 2010).

Nesse sentido a insuficiência da setorização de determinadas demandas de gênero como pautas a serem açambarcadas pela representação sindical (a exemplo da criação isolada de uma Secretaria de Mulheres que pensa atividades e pautas setorizadas no âmbito do sindicato) sem que a presença de mulheres, suas demandas e modos de luta atravessem todos os demais aspectos da construção sindical ${ }^{3}$. Daí exsurge o relevante debate sobre a necessidade de democratização interna dos sindicatos, desfazendo a centralização e a hierarquização entre homens e mulheres, e sua estreita relação com ações afirmativas, como as cotas nas diretorias.

A alteridade representada na fala das trabalhadoras, que veem o sindicato como "eles" em oposição a um "nós", se aprofunda quando tais sujeitos ostentam gêneros diferentes, aprofundando a perspectiva da invisibilização (SOUZA-LOBO, 2011).

Nesse cenário, vale dizer que a distância, a deslegitimação e o recuo da atuação sindical, foram percebidos de modo concreto por meio da experiência, concluindo-se que não

\footnotetext{
${ }^{3}$ A esse respeito, consultar: MARTINS, Milena Pinheiro; ALVES, Raíssa Roussenq. Em busca da participação igualitária: a implementação das cotas de gênero nas eleições sindicais e o exemplo da CUT. In: DELGADO, Gabriela Neves; PEREIRA, Ricardo Macedo de Brito (org.). Trabalho, Constituição e Cidadania: a dimensão coletiva dos direitos sociais trabalhistas. São Paulo: Ltr, 2014, pp. 298-313.
} 
apenas compõem um cenário global de derrocada do sindicalismo, mas são também respostas específicas à questão do trabalho terceirizado.

No intuito de impedir que as insatisfações se perdessem em face do desapontamento com a ação coletiva institucionalizada, foi construído um encontro do curso, voltado à ideia de organização coletiva para além das instituições sindicais. Para tanto, foram trazidas para as trabalhadoras experiências de organização autônoma desenvolvida por mulheres trabalhadoras terceirizadas, como elas, a fim de provocar o imaginário dessas mulheres a se deslocar em relação ao conformismo ou à relação de passividade e clientelismo em relação ao sindicato burocratizado.

Assim, realizou-se uma dinâmica que estava prevista para o projeto original do curso, que consistiu no compartilhamento de frases retiradas do livro "Precarização tem rosto de mulher", o qual relata a experiência de greve das trabalhadoras terceirizadas da USP no ano de 2010, e, a partir delas, se propôs a discussão sobre organização coletiva.

Entre as frases distribuídas, estavam "muda o chicote, mas quem bate é a mesma pessoa"; "a precarização escraviza, humilha e divide"; "se a gente reclamar, dizem que terceirizado é assim mesmo, e aí a gente tem que se conformar"; "nessa luta eu aprendi que não podia ter um patrão dentro de casa"; todas selecionadas previamente pelas estudantes, em debate e reflexão sobre a terceirização, a precarização, as dificuldades da organização coletiva em face da fragmentação promovida pelo capital, e, sobretudo, sobre a consubstancialidade das questões de raça, classe e gênero.

Diante da provocação, as trabalhadoras associaram os discursos, com os quais se identificaram, a situações colhidas da sua experiência, como, por exemplo, as alterações das linhas de ônibus sem a anuência dos próprios usuários do transporte público; a situação de humilhação vivenciada quando foram pedir liberação do trabalho nos sábados posteriores aos feriados. Discutiram também sobre os "desvios de função" e a lógica do "favor", nas relações de trabalho. Zelândia trouxe dois relatos: o primeiro envolvendo um trabalhador terceirizado lotado na escola de nutrição, que, "fazendo um favor", foi carregar um armário, teve um ferimento no dedo e a empresa não se responsabilizou, ao argumento de que ele não estava fazendo nada que fosse de sua função no trabalho. O segundo relato se referia a um rapaz que foi transferido de unidade porque, na sua hora de descanso, ele não estava disponível para "fazer um favor" ao diretor da unidade.

Foi trazida também insatisfação quanto à relação que os/as estudantes têm com os banheiros. As trabalhadoras relataram muitas situações extremamente desagradáveis envolvendo 
a limpeza dos banheiros, por conta da falta de higiene, cuidado e respeito dos usuários e usuárias do banheiro: "Pra mim foi uma humilhação", foi o que disse Sara depois de relatar uma situação concreta.

A discussão, portanto, envolveu provocações, por meio de elementos concretos de outras experiências de trabalho e luta, e a abertura do espaço de formulação acerca das próprias insatisfações, das prévias experiências de organização, ainda que tímidas (como a tentativa de descanso no sábado posterior ao feriado), e das dificuldades/possibilidades dessa organização.

É importante perceber como o momento de construção e de tomada de consciência dessas trabalhadoras, ainda muito incipiente em relação ao debate e a essas formulações, muitas vezes se limita ao verbalizar e organizar discursivamente os incômodos, sendo esse pequeno passo, todavia, imprescindível para um posterior avanço em relação a atitudes práticas e coletivas que a experiência educativa, também coletiva, impulsiona.

\section{Considerações finais}

Esse artigo reúne o relato e a reflexão sobre uma experiência universitária de formação de trabalhadoras terceirizadas da limpeza em direitos humanos e cidadania, no âmbito da Universidade Federal da Bahia, numa releitura da experiência desenvolvida em outras universidades brasileiras sob o título de "Promotoras legais populares".

No curso dessa experiência extensionista, que se estendeu por um ano, demissões em massa de trabalhadores surpreenderam os envolvidos, dando azo a mobilizações de estudantes, trabalhadores e professores, que permitiram debater criticamente as relações de trabalho terceirizado, numa experiência de formação e organização que teve o estudo do direito como mediador.

Assim como em outras experiências de organização, foi interessante perceber como essa vivência foi transformadora para as trabalhadoras envolvidas, a partir de como passaram a se enxergar e a se colocar dentro do espaço da Universidade, bem como proporcionou às estudantes engajadas no projeto não apenas um conhecimento muito mais complexo e qualificado da regulação das relações de trabalho, mas uma importante construção crítica a respeito daquelas mulheres invisíveis que antes apenas limpavam a Faculdade e passaram a ser conhecidas por seus nomes, suas histórias e sua condição de sujeitas.

A atividade proporcionou também rica investigação sobre a precarização do trabalho no âmbito do serviço público em razão da contratação terceirizada, e a perversa intensificação 
dessa degradação do trabalho a partir da consubstancialidade das questões de gênero, raça e classe.

\section{REFERÊNCIAS}

ASSUNÇÃO, Diana (org.). A precarização tem rosto de mulher: a luta das trabalhadoras e trabalhadores terceirizados da USP. São Paulo: Editora Expressão Popular, 2013.

DRUCK, Maria da Graça. Terceirização: (des)fordizando a fábrica. São Paulo: Boitempo, 1999 p. 227-230.

DRUCK, Graça; SENA, Geovana; ARAÚJO, Samia; PINTO, Marina. A Terceirização no serviço público: particularidades e implicações. In: Terceirização do trabalho no Brasil : novas e distintas perspectivas para o debate / organizador: André Gambier Campos. - Brasília: Ipea, 2018.

FONSECA, Lívia Gimenes Dias da. A luta pela liberdade em casa e na rua: a construção do Direito das mulheres a partir do projeto Promotoras Legais Populares do Distrito Federal. 2012. Dissertação (Mestrado em Direito) - Faculdade de Direito, Universidade de Brasília, Brasília.

GODINHO, Tatau. Ação afirmativa no partido dos trabalhadores. In: Revista de Estudos Feministas. Ano 4, $1^{\circ}$ sem/1996, pp. 148-157.

HOOKS, bell. Ensinando a transgredir: a educação como prática da liberdade. São Paulo: Martins Fontes, 2013.

INSTITUTO THEMIS (sítio virtual). Promotoras Legais Populares. Disponível em: http://themis.org.br/fazemos/promotoras-legais-populares

KERGOAT, D. Dinâmica e consubstancialidade das relações sociais. Novos estudos-CEBRAP, n.86, 2010, pp. 93-103.

MARCELINO, Paula Regina Pereira. Trabalhadores terceirizados e luta sindical. Curitiba: Appris, 2013

MARTINS, Milena Pinheiro; ALVES, Raíssa Roussenq. Em busca da participação igualitária: a implementação das cotas de gênero nas eleições sindicais e o exemplo da CUT. In: DELGADO, Gabriela Neves; PEREIRA, Ricardo Macedo de Brito (org.). Trabalho, Constituição e Cidadania: a dimensão coletiva dos direitos sociais trabalhistas. São Paulo: Ltr, 2014, pp. 298-313.

SOUZA-LOBO, Elizabeth. A classe operária tem dois sexos: trabalho, dominação e resistência. São Paulo: Editora Fundação Perseu Abramo, 2011.

TEIXEIRA, Marilane; LEONE, Eugênia. As mulheres no mercado de trabalho e na organização sindical. Trabalho apresentado no XVII Encontro Nacional de Estudos Populacionais, realizado em Caxambu - MG - Brasil, de 20 a 24 de setembro de 2010. Disponível

em: http://www.abep.nepo.unicamp.br/encontro2010/docs_pdf/tema_8/abep2010_2200.pdf Acesso em 4/8/2017, 11h18min 